\title{
De loochenaars van Auschwitz; de ongewenstheid van strafbaarstelling
}

\author{
Mr A.L.J. Janssens*
}

\section{Inleiding}

Met de regelmaat van de klok duiken er geschriften op waarin de genocide op de joden gedurende de Tweede Wereldoorlog wordt ontkend. Deze geschriften zijn afkomstig van auteurs die zichzelf historicus noemen, maar wier kennis van de geschiedenis weinig indruk maakt. Evenmin geven de schrijvers van dergelijke stukken blijk van enig respect voor de nabestaanden van de slachtoffers van de holocaust. Het wekt derhalve weinig verbazing dat publicaties waarin de volkerenmoord ontkend wordt, weerzin wekken.

Aangezien het niet denkbeeldig is dat openbaarmaking van 'revisionistische' opvattingen leidt tot een ontkenning van de op racisme geschoeide volkerenmoord - hetgeen een fundament zou kunnen zijn van een relativering van het gevaarzettende karakter van dat racisme - is de roep om strafbaarstelling van de ontkenning van de holocaust wel te begrijpen. ${ }^{2}$ Als de ontkenning geen strafbare belediging zou zijn, ligt het in de rede dergelijke gedragingen zelfstandig strafbaar te stellen. Daartoe dient een nieuw delict te worden geformuleerd. Dit zou de strafrechtelijke bescherming tegen racisme vervolmaken.

De vraag is of een strafrechtelijke reactie op de enkele ontkenning van de holocaust wel voor de hand ligt. Ik meen dat er geen behoefte bestaat aan een nieuwe strafbepaling waarin een dergelijke gedraging als delict sui generis strafbaar wordt gesteld. Evenmin lijkt mij de enkele leugen als een strafbare belediging te beschouwen. In deze bijdrage werk ik deze opvatting nader uit. In de eerste plaats licht ik toe waarom naar mijn mening de enkele ontkenning geen

* Docent bij de vakgroep Strafrecht \& Criminologie van de Rijksuniversiteit Groningen.

1 Met 'ontkenning van de holocaust' wordt, naast het regelrecht ontkennen van de gebeurtenissen, ook bedoeld die uitlatingen waarin weliswaar het discriminatoire karakter van het beleid der nazi's met betrekking tot joden, zigeuners etc. niet wordt ontkend, maar waarin de stelselmatige moord als een mythe wordt beschouwd (bijvoorbeeld omdat het in hun visie gewoonweg technisch onmogelijk zou zijn om miljoenen mensen in de gaskamers om te brengen).

2 Naar huidig recht is de ontkenning van de holocaust in elk geval strafbaar wanneer zij met beledigende uitlatingen gepaard gaat (art. 137c Sr). Vgl. HR 25-11-1997, NJ 98261 . Zie over deze uitspraak F. Janssens, De ontkenning van 'Auschwitz' en de strafwet, in: Delikt en Delinkwent 28 (1998), p. 565 e.v.; P. Rodrigues, Verspreidingssverbod ontkenning echtheid dagboek Anne Frank, in: LBR-Bulletin 1999, afl. 1, p. 28 e.v.. 
belediging in de zin van de strafwet is. In de tweede plaats zal ik, vanuit vier perspectieven bekeken, verdedigen waarom de ontkenning van de holocaust geen nieuw te creëren zelfstandig delict rechtvaardigt.

\section{Ontkenning van de holocaust is geen strafbare belediging}

Beledigend in de zin van de strafwet is die uitlating waarmee iemands morele integriteit wordt miskend. Een uitlating geldt als beledigend indien daarin de krenking van andermans reputatie besloten ligt of indien met de uitlating iemands waardigheid, welker erkenning men in het maatschappelijk verkeer mag verwachten, wordt miskend. ${ }^{3}$ Van een belediging in de zin van art. 137c Sr spreekt men, als die miskenning op bepaalde groepskenmerken stoelt. ${ }^{4}$

Waarom meen ik dat de ontkenning van de holocaust als zodanig geen belediging in de zin van de strafwet is? Zij treft immers de nabestaanden van de slachtoffers van de volkerenmoord recht in het hart. Niet te ontkennen valt dat de leugen hen kwetst of grieft. Maar iemand kwetsen of grieven is niet zonder meer strafbaar beledigen. Ik licht dit toe aan de hand van de ratio legis van art. 137c Sr. Deze houdt in: erkenning van het respect dat een groep mensen op grond van hun ras etc. in het maatschappelijk verkeer geniet. De publieke minachting miskent die erkenning en is daarmee beledigend. De vraag nu is, of ook de kwetsende of grievende uitlating dat is. Ik meen dat het niet ontzien van andermans gevoelens niet zonder meer neerkomt op het miskennen van zijn waardigheid. Er is een verschil tussen het miskennen van iemands waardigheid en gekwetst zijn. Gekwetst zijn is immers een innerlijk proces is, welks voltrekking zich aan de uiterlijke waarneming onttrekt. Het zou te veel van de strafrechter vergen om de krenking van iemands persoonlijke gevoelens aan een juridisch oordeel te onderwerpen.

Het miskennen van iemands waardigheid is iets anders. In wezen gaat het daarbij om uiterlijk vertoon van disrespect; het leidt tot devaluatie van iemands waardigheid. De belediger wil met zijn uitlating zeggen dat de beledigde de

3 Zie uitgebreid: A.L.J. Janssens, Strafbare belediging, Amsterdam (diss. Groningen), p. 387 e.v

4 Art. 137c Sr luidt: 'hij die zich in het openbaar, mondeling of bij geschrift of afbeelding, opzettelijk beledigend uitlaat over een groep mensen wegens hun ras, hun godsdienst of levensovertuiging of hun hetero- of homoseksuele gerichtheid, wordt gestraft met een geldboete van ten hoogste een jaar of geldboete van f10.000 gulden]. 
rechtens inherente waardigheid niet verdient. ${ }^{5}$ De loochenaar van 'Auschwitz' debiteert onzin, maar zegt daarmee niet zonder meer dat personen die zich gegriefd voelen door zijn ontkenning 'waardeloos' zijn. ${ }^{6}$

5 Vgl. Janssens, Strafbare belediging, o.c., p. 389; zie ook T. Rosier, Vrijheid van meningsuiting en discriminatie in Nederland en Amerika, Nijmegen, 1997 (diss. VU Amsterdam), p. 67.

6 Zie ook Hof Amsterdam 16-6-1994, gepubl. in Mediaforum 1994, nr. 4, p. 64. 
Men kan hier tegen aanvoeren dat de holocaust een bijzondere morele verantwoordelijkheid jegens de nabestaanden van de slachtoffers met zich meebrengt, hetgeen een aspect zou kunnen zijn van de joodse 'eer' of waardigheid. De enkele ontkenning van de holocaust zou een miskenning van het typische Joodse lot zijn en daarmee miskenning van hun joodse identiteit ${ }^{7}$ impliceren. Op die gronden zou die ontkenning beledigend in de zin van art. 137c Sr zijn.

Naar mijn mening is die conclusie onjuist. Als men al kan stellen dat de tragische gebeurtenissen van de Tweede Wereldoorlog tot de (kern van) de huidige Joodse identiteit behoren, dan betekent dat nog niet dat een andere - zij het onzinnige - lezing van de gebeurtenissen zonder meer ook de waardigheid van het joodse volk miskent. De joodse identiteit is niet zonder meer gelijk te stellen aan de rechtens te erkennen waardigheid van de joden. Ongetwijfeld kan iemands identiteit met zijn zelfrespect en eigenwaarde zijn verweven. Maar de krenking van iemands gevoel voor eigenwaarde impliceert niet zonder meer een gebrek aan respect. Voor strafbaarheid is een getoond gebrek aan respect, een verklaring van onwaarde vereist.

\section{Is een zelfstandige strafbaarstelling geïndiceerd?}

$\mathrm{Nu}$ ook in de rechtspraak wordt aangenomen dat de enkele ontkenning van de holocaust geen strafbare belediging oplevert, is de vraag gewettigd of de problematiek van de zogenaamde 'revisionisten' langs andere weg strafrechtelijk bestreden moet worden. ${ }^{8}$ Rechtvaardigt een niet te onderschatten (sociaal) probleem

7 Dit begrip is (te kort) te beschrijven als een voortdurend besef van uniciteit ten opzichte van andere groepen.

8 In onze buurlanden is dit geen vraag meer. In België is met de Wet van 23 maart 1995 de ontkenning, de schromelijke minimalisering en de rechtvaardiging van de holocaust strafbaar gesteld. De maximumstraf is éen jaar vrijheidsstraf. Tot veel veroordelingen heeft deze wet bij mijn weten niet geleid, wat wel opmerkelijk mag worden genoemd gezien het grote aantal publikaties van 'negationistische' aard die in België geproduceerd worden. Het delict is een persmisdrijf, welks pleger langs de weg van de omslachtige juryrechtspraak berecht wordt. In Duitsland is de 
een nieuw te formuleren strafbaarstelling? Hieronder verdedig ik de opvatting dat de wetgever zich daartoe niet moet laten verleiden. Vanuit vier gezichtspunten zal ik deze door de wetgever te betrachten terughoudendheid beargumenteren.

a. Het perspectief van het schadebeginsel als grond voor strafbaarstelling

ontkenning in art. 130 lid 3 Strafgesetzbuch strafbaar gesteld, met een maximumstraf van vijf jaar vrijheidsstraf. Zie met name over de Duitse beplaing en de kritische kanttekeningen daarbij: Janssens, De ontkenning van 'Auschwitz', o.c., p. 567 e.v.; S. Cobler, Das Gesetz gegen die 'Auschwitz'-lüge', in: Kritische Justiz 18(1995), p. 195 e.v. 
Een in de literatuur erkend en omschreven criterium voor strafbaarstelling is de schade die een gedraging zou kunnen aanrichten of daadwerkelijk aanricht. ${ }^{9}$ Morele schade - morele verontwaardiging - kan naar mijn mening geen grond voor strafbaarstelling zijn. ${ }^{10}$ Zou dat anders zijn, dan ligt de weg naar willekeurige strafwetgeving open. Bovendien zou dat betekenen dat de overheid afwijkende opvattingen 'officieel' zou weren en dat zij langs wettelijke weg heersende opvattingen overheersend zou willen maken. Het gevaar is bepaald niet denkbeeldig dat dan het strafrecht tot een soort overtuigingsrecht verwordt. De belediging berokkent naast morele verontwaardiging, ook schade: zij tast iemands reputatie aan en daarmee zijn positie in de samenleving. De miskenning van de waardigheid is vaak het voorportaal van daadwerkelijke ongerechtvaardigde achterstelling en zelfs van fysieke mishandeling. Zou de loochenaar van 'Auschwitz' zijn beweringen larderen met beschuldigingen of scheldwoorden, dan zou daarmee zijn gedraging zonder meer schadelijk zijn. ${ }^{11}$ De vraag is of de enkele ontkenning van de holocaust zodanig schadelijk is, dat zij strafbaarstelling rechtvaardigt. ${ }^{12}$ Duidelijk is dat de ontkenning een terechte verontwaardiging teweeg brengt. Het ontkennen van iets dat evident heeft plaatsgevonden en dat anderen zoveel leed heeft berokkend en de nabestaanden nu nog berokkent heeft daardoor onzedelijke trekken. Maar in het grieven van nabestaanden ligt, zoals gezegd, niet zonder meer de ontkenning van de waarde van iemand (op grond van zijn ras) besloten. Evenmin kan men stellen dat met de enkele ontkenning van 'Auschwitz', het poneren van een afwijkende mening, de rechtsorde dusdanig ondermijnd wordt dat strafrechtelijk ingrijpen geboden is. Het uitdragen van afwijkende - en soms onbegrijpelijke) mores is zelden aanleiding geweest tot het inroepen van het strafrecht; waarom zou dat met degene die onzin over 'Auschwitz' debiteert wel moeten gebeuren?

9 Zie bijvoorbeeld M. Groenhuijsen, Criteria voor strafbaarstelling, in: Delikt en Delinkwent 23(1993) 1, p. 1 e.v.

10 Anders: J.M. van Bemmelen, Positieve criteria voor strafbaarstelling, in: Speculum Langemeijer; 31 rechtsgeleerde opstellen (J.F. Glastra van Loon et al., red.), Zwolle, 1973, p. 13.

11 Zie C.W. Maris, Wanftidè, tuftamara; over vrijheid van meningsuiting en discriminatie, in: Vrijheid van meningsuiting; racisme en revisionisme (G.A.I. Schuijt et al., red.); 1995, p. 23; zie ook Janssens, Strafbare belediging, o.c., p. 401.

12 Men zal het met mij eens zijn dat de (integriteit van de) geschiedwetenschap is geen rechtens te beschermen belang. Meestal wordt dergelijk kaf op adequate wijze en doeltreffend door historici van het koren gescheiden. 
Men kan wijzen op de onrust die de loochenaar zaait. De schade zou gelegen kunnen zijn in het gevoel van onveiligheid dat daardoor in het leven wordt geroepen en waarin de overheid lijkt te berusten, als niet wordt ingegrepen. Om die redenen zijn de Belgische en de Duitse wetgever overgegaan tot het zelfstandig strafbaar stellen van de enkele ontkenning van de holocaust. In beide buurlanden vindt de productie en verspreiding van negationistische lectuur op veel grotere schaal plaats dan in Nederland; Duitsland torst bovendien zijn verleden. Men heeft in beide landen onder ogen gezien dat de ontkenning van de holocaust het begin van een briesje zou kunnen zijn, dat, als zij onweersproken blijft, tot een fikse storm kan uitgroeien. Als die ontkenning ruim baan krijgt zal het gevoel van veiligheid afnemen. Daarin ligt - zo zou een pleidooi voor strafbaarstelling van de ontkenning kunnen vervolgen - de schade besloten: de bedreiging van de openbare orde.

De argumenten tegen strafbaarstelling zijn gelegen in dit pleidooi: De hier te lande betrekkelijk weinig voorkomende uitlatingen van deze snit worden in de regel onmiddellijk en deskundig weersproken. Een strafrechtelijke veroordeling voegt dan niet alleen weinig toe, zij zou zelfs ook de discussie over dit onderwerp in de kiem smoren. Met Maris meen ik namelijk dat het van wijsheid zou getuigen in te zien waarom de ontkenning van de holocaust tot xenofobie kan leiden. Het onzichtbaar maken van de ontkenning door middel van een verbod leidt tot een verminderd inzicht in het gevaar van racisme. ${ }^{14}$ Strafbaarstelling maakt zo'n discussie overbodig.

\section{b. Het perspectief van de vrijheid van meningsuiting}

Vanuit het perspectief van de vrijheid van meningsuiting ligt de strafbaarstelling van de enkele ontkenning van de holocaust niet voor de hand. Ik meen dat ook de leugen door dit grondrecht wordt beschermd. Niemand zal bijvoorbeeld verdedigen, dat wie van mening is dat de zon rond de aarde draait, geen vrijheid van meningsuiting heeft. De vrijheid van meningsuiting is, zo stelt Raes terecht, neutraal $^{15}$ : Ook opvattingen die gemeenlijk niet gekoesterd worden, genieten

13 Vgl. A. Mulder, Aantasting van de openbare orde, in: Gedenkboek honderd jaar Wetboek van Strafrecht (J.P. Balkema et al., red.), Arnhem, 1986, p. 373.

14 Maris, o.c., p. 26.

15 K. Raes, Vrijheid van meningsuiting en de revisionistische geschiedvervalsing, in: 
bescherming. Het grondrecht van de vrijheid van meningsuiting normeert principieel niet naar inhoud; het behoort met betrekking tot het te beschermen recht de waarheid niet van de leugen te onderscheiden. ${ }^{16}$ Strafbaarstelling van bepaalde uitlatingen zou dat principe miskennen.

Vrijheid van meningsuiting; racisme en revisionisme (G.A.I. Schuijt et al., red.); 1995, p. 39; zie ook Janssens, Ontkenning, o.c., p. 574.

16 Blijkens Duitse jurispudentie wordt daarover bij onze Oosterburen wel anders gedacht. In een uitspraak van het Bundesverfassungsgericht van 13 april 1994 werd overwogen dat de ontkenning van 'Auschwitz' niet binnen het bereik van art. 5 Grundgesetz zou vallen, omdat een meningsuiting een stellingname tot de inhoud van de uitlating veronderstelt. De weergave van feiten is een meningsuiting, wanneer deze tot de meningsvorming bijdraagt. Leugens, evidente onwaarheden, dragen daar niet toe bij en vallen daarom buiten de bescherming van art. $5 \mathrm{GG}$, aldus beknopt weergegeven de overwegingen van het duitse hof. Uit het vooraf weergegevene volgt dat ik deze conclusie niet deel.

38 
Hiermee hangt samen de idee dat het debat, de motor van een democratische samenleving, gevoed wordt met opvattingen die tegen de heersende mores ingaan en die misschien zelfs aperte onzin zijn. In een pluriforme samenleving moeten burgers op grond van uit allerlei hoeken en gaten aangereikte opvattingen, stellingnamen en meningen kritisch kunnen reflecteren over waarheidsmonopolies en waardeaanspraken. Dat wil zeggen dat deze meningen etc. geverifieerd en gefalsificeerd moeten kunnen worden. Een confrontatie van tegenstrijdige stellingnamen dwingt tot een beoordeling ervan en dus uiteindelijk tot een nieuw oordeel: 'De wereldbeschouwing moet vanuit een vergelijkende confrontatie worden verdiept ${ }^{17}{ }^{17}$ In deze optiek is de beperking van de vrijheid van meningsuiting een aanslag op de waarheidsvinding.

Hiermee wil ik niet zeggen dat de overheid zelf neutraal behoort te staan tegenover bepaalde waarden. Er is een verschil tussen waardeneutraliteit waar het gaat om het uiten van allerlei opvattingen en neutraliteit waar het gaat om de inhoud ervan. De overheid behoort burgers de vrijheid te geven hun opvattingen uit te dragen, zonder dat de overheid af hoeft te zien van het hebben en uitdragen van haar eigen opvattingen.

Uit bestendige Straatsburgse rechtspraak over art. 10 EVRM blijkt dat het EHRM deze liberale visie op het publieke debat eveneens verdedigt: meer dan eens heeft het EHRM overwogen dat uitspraken die 'shock, disturb and offend' niet onnodig gesmoord moeten worden door ze strafrechtelijk te verbieden. Daar is in de Straatsburgse opvatting alleen dan ruimte voor, als door de uitlating andermans rechten met voeten worden getreden. ${ }^{18} \mathrm{Ik}$ voeg hieraan toe dat meerdere malen de (voormalige) Europese Commissie, destijds het voorportaal van het Europese Hof, een nationale veroordeling op grond van de ontkenning van de holocaust, niet strijdig heeft geacht met art. 10 EVRM. Die uitspraken betroffen allen ontkenningen die gepaard gingen met regelrechte beledigingen aan het adres van de joden; zij werden namelijk bestempeld als zwendelaars en oplichters die de leugen verspreiden.

\section{c. Het perspectief van de effectiviteit van strafbaarstelling}

Vanuit een meer rechtssociologische invalshoek kan mijns inziens verdedigd worden dat van de strafbaarstelling van de enkele ontkenning van de holocaust niet vreselijk veel valt te verwachten - tenzij men genoegen neemt met wetgeving die slechts als verspreider van overheidsopvattingen fungeert.

Ik meen namelijk dat verwerpelijke en in elk geval onjuiste visies op de historische werkelijkheid niet zullen verdwijnen door deze strafrechtelijk te verbieden. $\mathrm{Nu}$ is het uiteraard de vraag of zo'n argument volstaat tegen strafbaarstelling. Het verwerpelijke verschijnsel diefstal is immers ook niet uit de

17 Raes, o.c., p. 36.

18 Zie over art. 10 EVRM en de relevante jurisprudentie: Janssens, Strafbare belediging, o.c., p. 283 e.v. 
wereld geholpen; toch zullen weinigen geneigd zijn om die reden de onmiddellijke afschaffing van art. $310 \mathrm{Sr}$ te bepleiten.

Ik denk echter dat dit argument tegen de strafbaarstelling van de enkele ontkenning van de holocaust niet direct daarom weggemoffeld moet worden. Als namelijk het beoogde effect van een strafbaarstelling is dat de loochenaar op andere gedachten wordt gebracht, kan het resultaat wel eens tegenvallen. Rechtssociologische literatuur ondersteunt dit vermoeden. Een wet waarin de ontkenning van de holocaust strafbaar wordt gesteld zou, kort gezegd, tot doel hebben het openbaren van opvattingen die bijdragen aan vreemdelingenhaat en racisme tegen te gaan. Dat doel vindt geen grond in empirisch gefundeerde theorieën over hoe bepaalde ideeën zich verspreiden. ${ }^{19}$ Zonder dergelijke wetenschap berust strafbaarstelling dus op drijfzand. Overschatting van de mogelijkheden van het strafrecht kan bijna niet anders dan tot teleurstellingen en frustraties leiden, die de geloofwaardigheid van de overheid wezenlijk kunnen ondermijnen. Bovendien zou het zelfstandig strafbaar stellen van de 'Auschwitzlüge' van weinig vertrouwen getuigen in de corrigerende en wellicht ook normerende kracht van het wetenschappelijke of politieke debat.

Daarbij moet overwogen worden dat strafbaarstelling van de Auschwitzlüge en de daarop gebaseerde vervolgingen en veroordelingen ook ongewenste effecten kunnen sorteren: het in het leven roepen van martelaarschap en - wat erger is aandacht voor en dus verspreiding van dergelijke de Auschwitzlüge.

d. Het perspectief van de vergelijking van leed

De tragische gebeurtenissen rond de joodse burgers van Europa staan bepaald niet op zichzelf. Genocide is helaas geen unieke gebeurtenis. Ook de zigeuners en de homo's werden door de nazi's stelselmatig de dood in gejaagd. Voor en nog ruim na de Tweede Wereldoorlog zijn tallozen het slachtoffer geweest van de stalinistische terreur. De gebeurtenissen in Oost-Afrika in 1994 staan nog op het netvlies gebrand. De etnische zuivering in Kosovo heeft inmiddels genocidale trekken aangenomen.

Strafbaarstelling van de ontkenning van de holocaust is zo bezien slechts een opportunistisch begin. Nabestaanden van andere slachtoffers dan die van de holocaust zouden om bijzondere bescherming kunnen gaan vragen. Nog bezwaarlijker acht ik echter de vergelijking van ellende. Is de holocaust 'erger' dan de volkerenmoord op de Armeniërs in 1915? Moet, als Kosovaren over pakweg zo'n twintig jaar nog deel uitmaken van de Nederlandse rechtsorde, de ontkenning dat aan het einde van de twintigste eeuw 'etnische zuiveringen' met hun gruwelijke gevolgen hebben plaatsgevonden, bij wet verboden worden? Eigen met andermans leed vergelijken en een pikorde van ellende opstellen heeft op zichzelf immorele trekken. ${ }^{20}$ Strafbaarstelling van de enkele ontkenning van de holocaust leidt ontegenzeggenlijk tot heilloze discussies hierover.

19 Vgl. Raes, o.c., p. 62.

20 Raes spreekt in dit verband van strijd met het non-discriminatiebeginsel (o.c., p. 72). 


\section{Conclusie}

Dat de ontkenning van de holocaust op domheid berust, behoeft geen betoog. De stelling dat de loochenaar weersproken moet worden zal evenmin op tegenstand stuiten. De vraag is echter of dat tegenspreken langs de weg van het strafrecht dient te gebeuren. Ik meen dat dat onwenselijk is. Zo'n strafbaarstelling miskent de principiële werking van de vrijheid van meningsuiting. Bovendien valt niet in te zien dat de enkele ontkenning van de holocaust dusdanig schadelijk is, dat op grond daarvan strafbaarstelling geïndiceerd is. Verder kan men zich afvragen of zo'n nieuw delict wel het gewenste effect zal bereiken. Ik vrees dat zo'n bepaling makkelijk te schrijven is, maar des te moeilijker valt te handhaven.

Ik meen dat de exegesen van de geschiedenis door revisionisten of negationisten heel goed door historici zijn te bestrijden; historici zijn bij uitstek degenen die hen de plaats toewijzen die hen toekomt: in de hoek. Bovendien moet men de kracht van het politieke debat niet onderschatten; het feit dat extreem-rechtse partijen vooralsnog niet in Nederland aanslaan is niet het gevolg van een of ander verbod, maar van de langs het publieke debat tot stand gekomen overtuiging dat deze partijen uiteindelijk niets te bieden hebben. Zo moet men ook met de loochenaars van Auschwitz omgaan. 